\title{
The Morphological Characteristics of the Particles of Woody Biomass Pulverized by Three Kinds of Mills
}

\author{
Chengbao $\mathrm{WU}^{1, a^{*}}$, Guosheng GAI ${ }^{2, b}$, Yufen YANG ${ }^{2, c}$, Lieshu $\mathrm{LIN}^{1, d}$ and \\ Zhenghua $\mathrm{CHEN}^{3, \mathrm{e}}$ \\ ${ }^{1}$ School of Aircraft Maintenance and Engineering, Guangzhou Civil Aviation College, Guangzhou \\ 510430, China \\ ${ }^{2}$ School of Materials Science and Technology, Tsinghua University, Beijing 10084, China \\ ${ }^{3}$ Maintenance Engineering Department, Guangzhou Baiyun International Airport Ground Servicing \\ LTD. Company, Guangzhou 510470, China \\ aemail:wuchengbao@caac.net, bemail:gaigs@139.com, cemail:yangyufen@mail.tsinghua.edu.cn, ${ }^{\mathrm{d}}$ \\ email:linlieshu@caac.net, ${ }^{\mathrm{e} e m a i l}$ :steffens@163.com
} Keywords: Morphological Characteristics, Woody Biomass, Universal Mill, Cutting Mill, The Cage
Mill

\begin{abstract}
The wood biomass with certain moisture content prepared by spraying artificially was pulverized by universal mill, cutting mill and the cage mill with the drying and transporting gas. The morphological characteristics of powder of the wood biomass with different moisture content were investigated by the scanning electrical microscope (SEM). The results indicated that particles of woody biomass pulverized by the cutting mill were flank and their cross sections of breakage were neatly, the breakage cross sections of those pulverized by the universal mill were rough, and the morphology of the particles of the woody product pulverized by cage mill was smooth, rounded, and their inner structure was deformed. When the moisture content was $0 \%$, the specific energy consumption of the cutting mill, the cage mill and the universal mill was 47.00, 120.99 and 158.48 $\mathrm{kWh} / \mathrm{t}$, respectively; as the moisture content was 20\%, the specific energy consumption of the cutting mill, the cage mill and the universal mill was 90.76, 255.47, $213.53 \mathrm{kWh} / \mathrm{t}$, respectively.
\end{abstract}

\section{Introduction}

Biomass is a kind of energy which is fixed and stored in the organisms by means of Photosynthesis and transforming the solar energy to chemical energy [1]. The biomass derived mainly from agricultural wastes, forest biomass. The technology of biomass transformation includes liquefaction [2], gasification [3], pyrolysis [4], fermentation [5] [6], combustion [7], and so on. The development of bioenergy attracts the attention of the countries all over the world as it has a series of advantages. The biomass is renewable and widely distributed. What's more, the use of biomass won't add the net increase of carbon dioxide. The utilization of biomass can effectively mitigate the pressure of the energy, reduce the air pollution and greenhouse effect, and reduce environmental problems caused by the extensive use of fossil fuels and biomass waste in agriculture and forest. It's expected that the biomass will take up about $40 \%$ of the global energy.

The biomass needs to be pulverized before effectively used [8]. After pulverized, the biomass particle become smaller and the specific surface area will increase a lot, which can improve the speed of chemical reaction. Generally speaking, the finer the particle is, the better the effects are during the further processing. The conventional pulverization of wood biomass usually consumed a large amount of energy, and its process was avoided by many users and researchers. Therefore, only a few processes used pulverized wood biomass or only a few research papers studied about wood biomass pulverization at the present time. In the previous research [9], the pulverizing characteristic of woody biomass by a kind of impact mill, and many important results were found. In the present work, the morphology characteristic of particle of the biomass and the relationship between the specific energy consumption and morphology of the particle of the biomass product was discussed. 


\section{Experimental}

Material. There are varieties of raw material of biomass, for the application reason, we are concentrated on the selected woody chip from the process industries. The experiment will be based on the woody chip from furniture industry. The biomass used for the experiment is woody chip from the furniture making factory, and its particle size were about $5 \mathrm{~mm}$.

Pretreatment of Woody Biomass. After picked out the sand, metal scrap and wood blocks, the woody chip was separated evenly on the plastic sheet and dried naturally for one day in the sunshine. Then, the woody chip was put into the plastic bags for storage.

To investigate the morphological characteristics of the woody chip with different moisture content, the dried woody biomass was spayed certain amount of water for pulverizing experiment. The moisture contents of the materials were $0,20 \mathrm{wt} \%$ respectively, the images of them were showed in Fig.1.

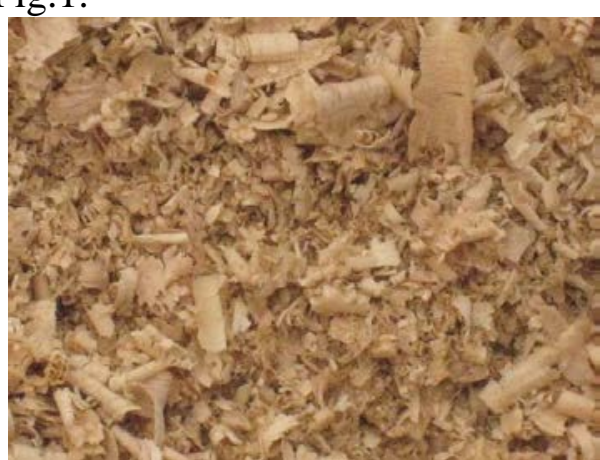

(a)

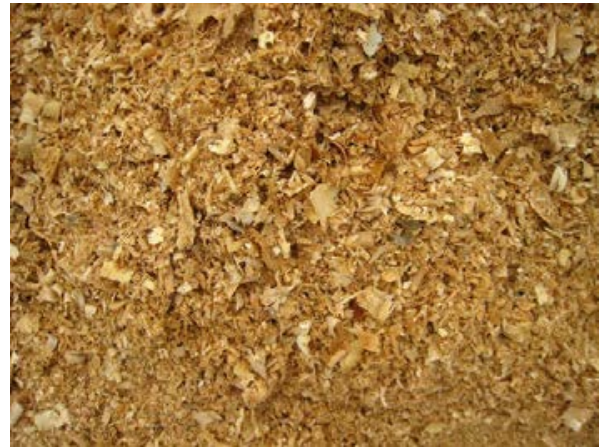

(b)

Fig.1 the woody chip with the different moisture content: (a) 0\%, (b) $20 \%$

After kept in plastic bags for $24 \mathrm{~h}$ to make the moisture homogeneously, the water-bearing woody biomass were prepared to be pulverized.

The Universal Mill (Impact Mill). The main pulverizing machine is universal mill. Main Motor Power is $3 \mathrm{~kW}$. The processing chart of the universal mill as Fig. 2 shows:

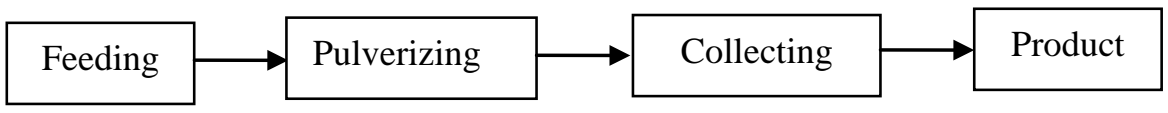

Fig. 2 the pulverizing process chart for universal mill

The speed and powder of the universal mill, the diameter of the hammer

The Cutting Mill. The main machine is cutting mill. The main motor power is $3 \mathrm{~kW}$, with a rotary cutter of $350 \mathrm{~mm}$ in diameter and $400 \mathrm{~mm}$ in length. Two rows of cutting tooth are mounted. Product size is controlled by screen in the bottom. The screen size is $1.2-1.6 \mathrm{~mm}$. The processing chart as follows:

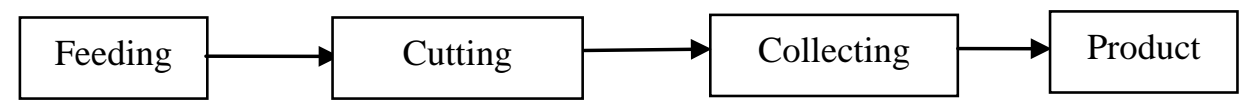

Fig.3 the pulverizing process chart for cutting mill

The Cage Mill (Shear Mill). Main Motor Power of the cage mill is $22 \mathrm{~kW}$. The speed is 2700 $\mathrm{rpm}$. The drying process is easy to combine with this kind of machine, by the passing through of hot air. The processing chart as follows:

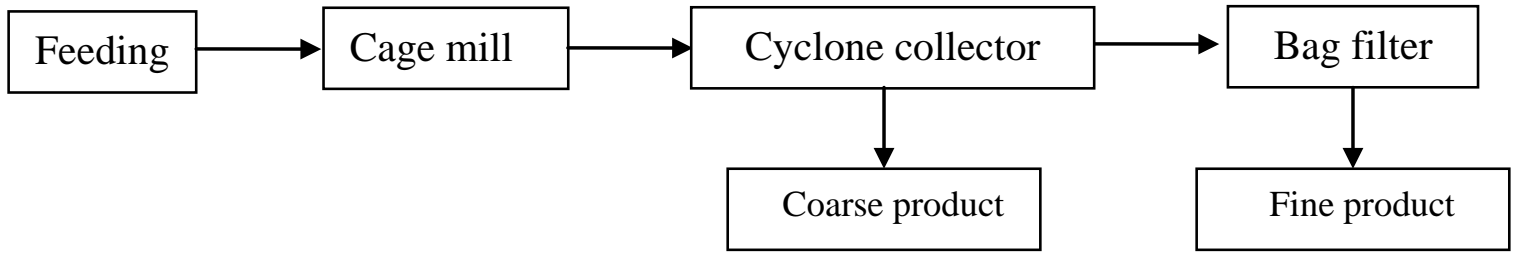

Fig. 4 the pulverizing process chart for the cage mill

Sample Analysis. Dividing the product of the experiments by the following method until in to $1 \mathrm{~kg}$ sample, Put the biomass product on a piece of plastic sheet to form a cone, then use a board to press it as a circular truncated cone. Cut the circular truncated cone into four equal portions across 
center shaft, and then remove the two diagonal parts. Heap the remaining two parts into a new cone, and cut into four parts again by the above method. Stop the sampling until the remaining biomass product was about $300 \mathrm{~g}$.

\section{Results and Discussion}

The SEMs of the woody product pulverized by cutting mill with different moisture content were shown in Fig.5.

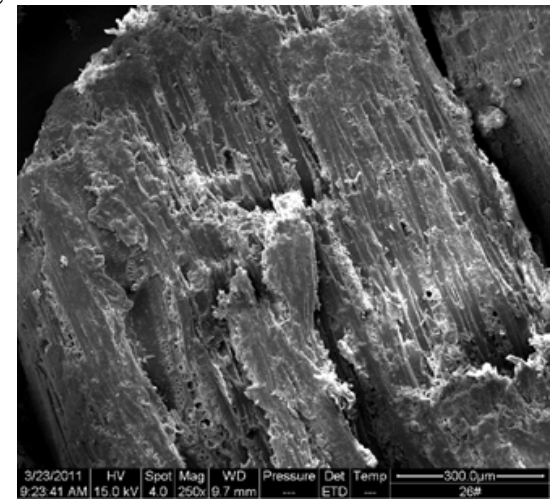

(a)

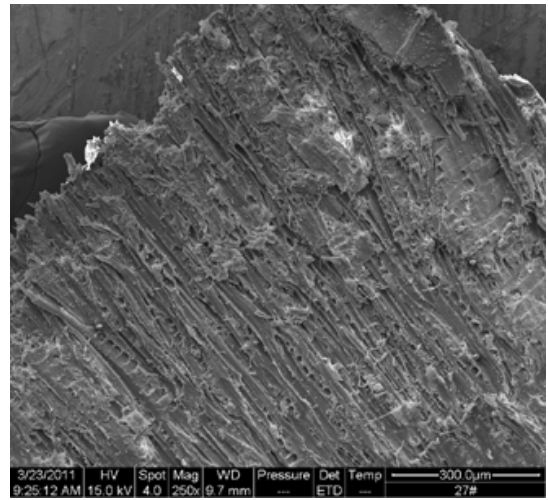

(b)

Fig.5 SEMs of the woody product pulverized by cutting mill with different moisture content: (a) $0 \%$, (b) $20 \%$

It can be seen from the Fig. 5 that the particle is flank and the cross section of breakage can be seeing neatly, it means that there is less energy is used to make the particle deformed, and the surface of the particle is sheared between the lingo cellulosic fiber cells. That is to say, the moisture content is little, the woody chips are crispy and brittle, the specific energy consumption is responding little. When the moisture content is $0 \%$, the specific energy consumption is $47.00 \mathrm{kWh} / \mathrm{t}$, as the moisture content reaches to $20 \%$, the specific energy consumption increases to $90.76 \mathrm{kWh} / \mathrm{t}$.

Fig. 6 shows the morphology of the woody product pulverized by universal mill with different moisture content.

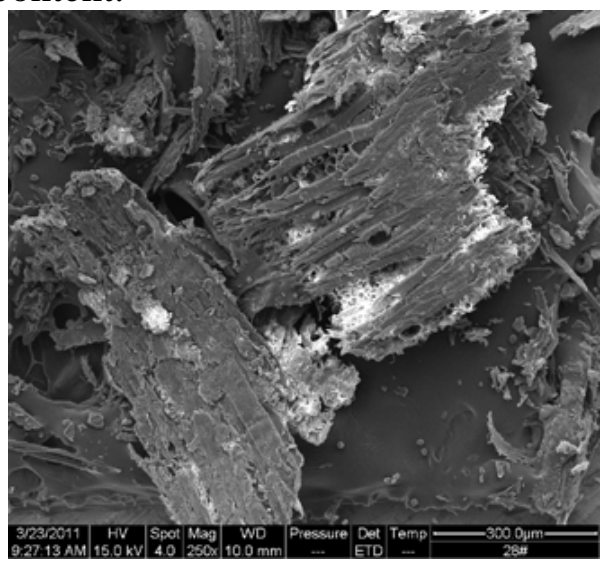

(a)

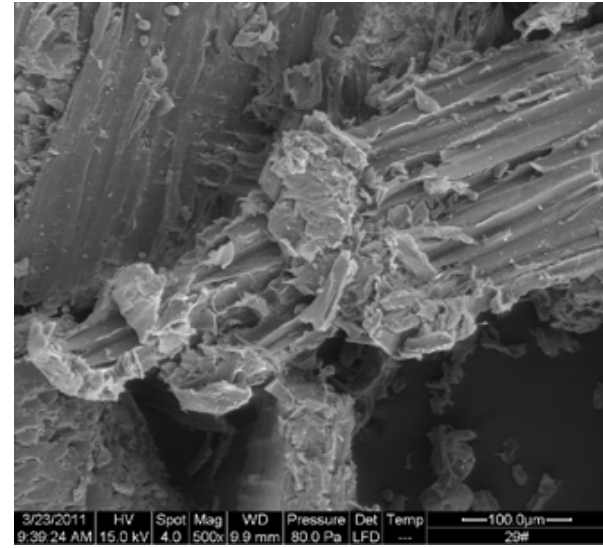

(b)

Fig.6 SEMs of the woody product pulverized by universal mill with different moisture content: (a)

$$
0 \% \text {, (b) } 20 \%
$$

The Fig.6 shows that the breakage cross section of the woody product pulverized by universal mill is rough, which indicate the pulverizing force bend the particles until the breakage occur in the middle of the particle. If the moisture content is higher, the biomass becomes much tougher and more plastic, the breakage cross section has the phenomena of soft shear deformation. That means the more energy is wasted on the deformation of the particles. When the moisture content is $0 \%$, the specific energy consumption is $120.99 \mathrm{kWh} / \mathrm{t}$; as it is $20 \%$, the specific energy consumption is $255.47 \mathrm{kWh} / \mathrm{t}$.

The SEMs of the woody product pulverized by cage mill with different moisture content is shown in Fig.7. From the SEMs (as Fig.7 shows), we can know that the particles have no sharp 
edge and corner, the particles are smooth, rounded, and their inner structure is also deformed. That is the reason that the biomass has a long way to go in the pulverizing chamber, the particles are acted by the severe friction and shear forces. If the moisture content is higher, this phenomenon is much clearer. That is, much more power energy is wasted to deform the particle. Therefore, the specific energy consumption is $158.48 \mathrm{kWh} / \mathrm{t}$ as the moisture content is $0 \%$, and increases to 213.53 $\mathrm{kWh} / \mathrm{t}$ at the moisture content of $20 \%$.

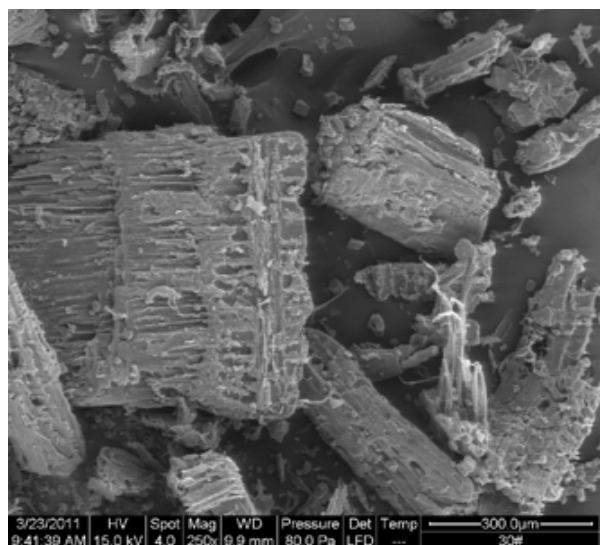

(a)

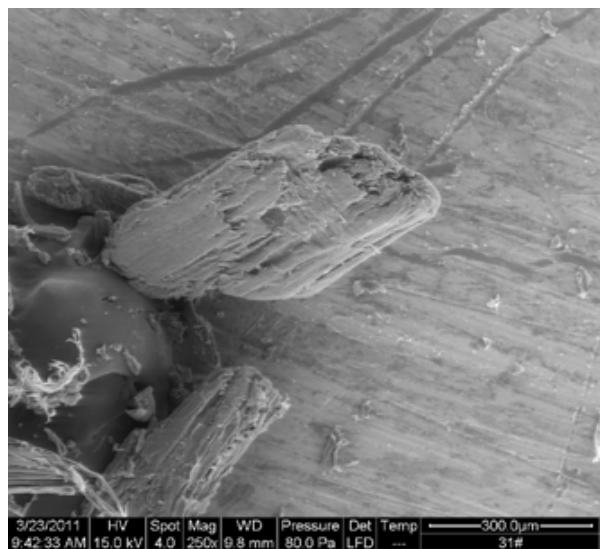

(b)

Fig.7 SEMs of the woody product pulverized by cage mill with different moisture content: (a) $0 \%$, (b) $20 \%$

\section{Conclusions}

The morphology of the particles of the woody biomass pulverized by different mills were not same: those pulverized by the cutting mill were flank and their cross section of breakage was neatly, the breakage cross section of the woody product pulverized by the universal mill was rough, and the particles of the woody product pulverized by cage mill had no sharp edge and corner, the morphology is smooth, rounded, and the their inner structure was deformed.

The specific energy consumption of universal mill was largest, that of the cutting mill was smallest. The higher the moisture content was, the larger the specific energy consumption was for the same mill.

\section{References}

[1] X.F. Zhang, H.Q. Li, L.F. Liu, R. Zeng, G.Q. Zhang, Analysis of a feasible trigeneration system taking solar energy and biomass as co-feeds, [J]. Energy Conversion and Management, 2016, 122, 74-84

[2] D.C. Elliott, P. Biller, A.B. Ross, A.J. Schmidt, S.B. Jones, Hydrothermal liquefaction of biomass: Developments from batch to continuous process, [J]. Bioresource Technology, 2015, 178,:147-156.

[3] D.D. Yao, Q. Hu, D.Q. Wang, H.P. Yang, C.F. Wu, X.H. Wang, H.P. Chen, Hydrogen production from biomass gasification using biochar as a catalyst/support, [J]. Bioresource Technology, 2016,216:159-164.

[4] P.A. Case, C. Truong, M.C. Wheeler, W.J. DeSisto, Calcium-catalyzed pyrolysis of lignocellulosic biomass components, [J]. Bioresource Technology, 2015,192: 247-252.

[5] D.W. Cho, S.H. Cho, H. Song, E.E. Kwon, Carbon dioxide assisted sustainability enhancement of pyrolysis of waste biomass: A case study with spent coffee ground, [J]. Bioresource Technology, 2015,189:1-6.

[6] N. Gopalan, K.M. Nampoothiri, G. Szakacs, B. Parameswaran, A. Pandey, Solid-state fermentation for the production of biomass valorizing feruloyl esterase, [J]. Biocatalysis and 
Agricultural Biotechnology, 2016, 7: 7-13.

[7] J. Li, M.C. Paul, P.L. Younger, I. Watson, M. Hossain, S. Welch, Prediction of high-temperature rapid combustion behaviour of woody biomass particles, [J]. Fuel, 2016, 165: 205-214.

[8] M.A. Saeed, C.H. Medina, G.E. Andrews, H.N. Phylaktou, D. Slatter, B.M. Gibbs, Agricultural waste pulverized biomass: MEC and flame speeds, [J]. Journal of Loss Prevention in the Process Industries, 2015,36: 308-317.

[9] C.B. Wu, G.S. Gai, Y.F. Yang, Z.X. Shang, Pulverizing characteristic of woody biomass by a kind of impact mill, [D]. International Conference on Automanical and Computational Engineering,2015:2253-2258. 